Cite this article: Tartaglia G M, Sforza C. Full-mouth Zirconia-based Implant-supported Fixed Dental Prostheses. Five year - results of a Clinical Pilot Study. Stoma Edu J. 2014; $1(2)$ 138-143.

\section{FULL-MOUTH ZIRCONIA-BASED IMPLANT-SUPPORTED FIXED DENTAL PROSTHESES. FIVE YEAR - RESULTS OF A CLINICAL PILOT STUDY.}

https://doi.org/10.25241/stomaeduj.2014.1(2).art.9

\section{Gianluca Martino Tartagliaa, Chiarella Sforza ${ }^{b^{\star}}$}

LAFAS, Laboratorio di Anatomia Funzionale dell'Apparato Stomatognatico, Dipartimento di Scienze Biomediche per la Salute, Facoltà di Medicina e Chirurgia, Università degli Studi di Milano, Milano, Italy

a. DDS, PhD, Assistant Professor and Consutant b. MD, PhD, Professor
Received: 30 August 2014 Accepted: 11 September 2014

* Corresponding author:

Professor Chiarella Sforza, MD, PhD

Dipartimento di Scienze,

Biomediche per la Salute, Facoltà di Medicina e Chirurgia, Università degli Studi di Milano, Milano, Italy.

via Luigi Mangiagalli 31, I-20133 Milano, Italy. Tel. +390250315385

Fax +390250315387 e-mail: chiarella.sforza@unimi.jt

\section{Abstract}

Introduction: Full-mouth reconstruction using dental implants and CAD-CAM prosthodontic procedure is a new option model in oral rehabilitation. One of the most consolidated promising material is yttria-stabilized tetragonal zirconia polycrystals, usually called "zirconia". It is chemically derived from zirconium sand, partially stabilized with yttrium, and then mechanically pressed into zirconia blocks that are used for CAD-CAM technology. In this paper we provide the 5-year results from a pilot study on full-mouth implant-supported zirconia-based fixed dental prostheses (FMIZBRs).

Methodology: Five women aged 55-75 years had received FMIZBRs from the same private practice. At the 5-year follow up visit, restorations remained in situ and were still in use.

Results: There were no failures and no biological complications during the follow-up period ( $100 \%$ survival rate). Eight FMIZBRs experienced some minor porcelain veneer fractures that were easily polished. None of the fractures impaired function or aesthetics. The patients were fully satisfied with the treatment.

Conclusion: Results from this pilot study suggest that FMIZBRs can be a treatment option that is rapidly shaping the coming dental rehabilitation area on implants.

\section{Keywords:}

Oral rehabilitation, zirconia, full-mouth prostheses, implants, chipping

\section{INTRODUCTION}

Full-mouth reconstruction using dental implants and CAD-CAM prosthodontic procedure is a new option model in oral rehabilitation. This clinical option could be used to overcome vertical and horizontal bone resorptions and it could include the gingival area. In this case it is possible to regenerate or, as an alternative, to replace lost tissue using prosthodontic reconstruction that restores the function and the esthetics of the gingiva and teeth. Various materials and techniques have been proposed to manufacture this type of restoration.

During the last years the consolidate extensive evidence of the excellent long-term results of traditional metal-ceramic prostheses (1) has started being compared with shortterm clinical analysis of implant-retained fixed prosthodontics manufactured from materials different from gold alloys. The rationale of using alternative materials to conventional metals is based on both the potential adverse reaction against gold (2) and the market demand of materials with improved esthetics. One of the most consolidated promising material is yttria-stabilized tetragonal zirconia polycrystals (Y-ZTP), usually called "zirconia". It is chemically derived from zirconium sand, partially stabilized with yttrium, and then mechanically (first axially and then isostatically) pressed into zirconia blocks that are used for CAD-CAM technology.

Y-ZTP fixed dental prostheses have become popular for their biocompatibility, the limited bacterial colonization and good aesthetic properties, and also for their predictable use with 


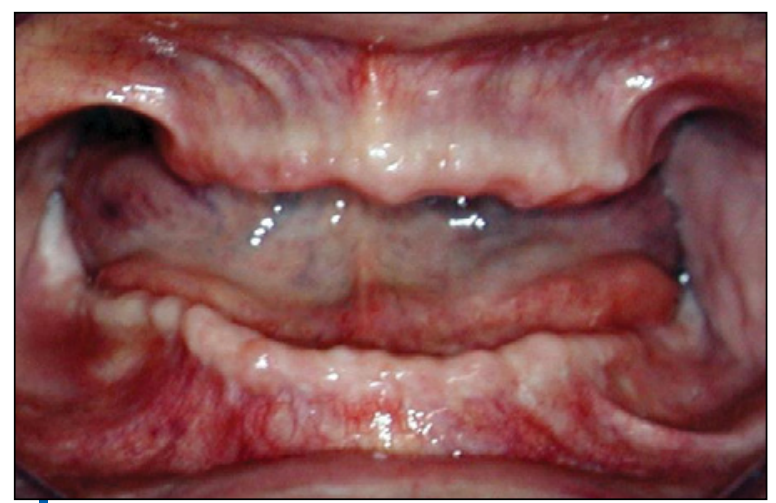

Figure 1. Patient M.A. (female, 68 y). Intraoral photograph before surgery, frontal view

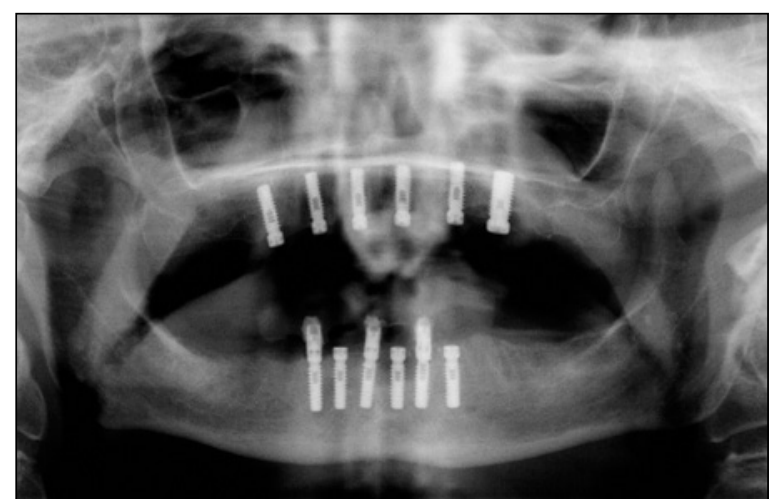

Figure 2. Patient M.A.

Immediately post-surgery X-ray

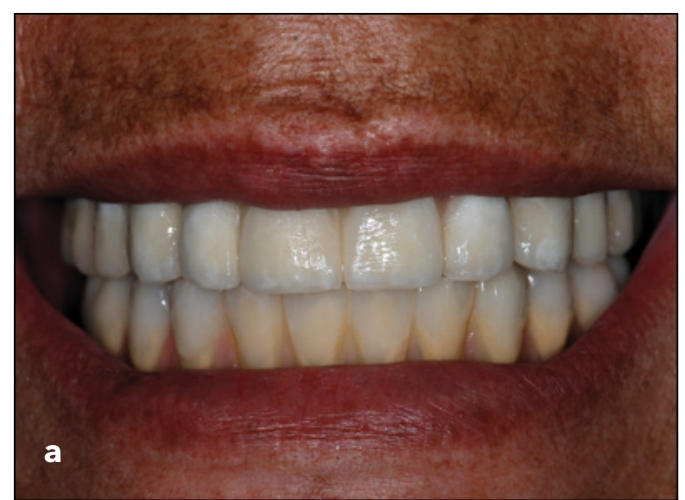

Figure 3 a, b. Patient M.A.

Frontal and lateral smile with the final prostheses
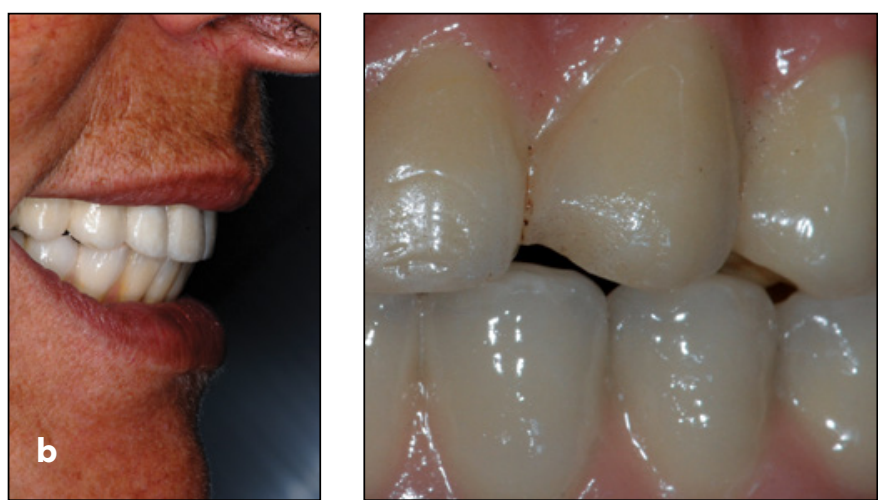

Figure 4. Patient M.A. Chipping complication at the two-years recall visit. The chipped surface was polished with patient's satisfaction the CAD-CAM manufacturing dental technique. Nonetheless, some problems are still unsolved. In particular, technical complications like framework fracture and veneering porcelain chipping $(3,4)$ also in case of implant-supported zirconia-based fixed dental restorations $(5,6)$. Different methods have been suggested to solve the problem of chipping veneering porcelain. In brief they could be summarized as follows:

- use of anatomically contoured framework design with respect to the veneering ceramic thickness necessity (between 1.5 to $2 \mathrm{~mm}$ ) (7);

- slow heating and cooling regimes when porcelain is fired on zirconia (8); (9);

- the press-over veneering material technique

- the sintering technique where CAD-CAM lithium disilicate veneer is linked to a zirconia framework (10).

The clinical necessity to collect data in order to understand, control and avoid the high percentage of chipping (40\%) that occur in full-mouth implantsupported zirconia-based fixed dental prostheses (FMIZBRs) (11) is the objective of this clinical trial.

In this paper we provide the 5-year results of a pilot study on FMIZBRs.

\section{MATERIALS AND METHODS}

\section{Patient selection}

Between March and July 2014 five women aged 55-75 years were selected from dental hygiene clinical recall appointments in a private Milan dental clinic. They all had received FMIZBRs from the same private practice between January 2008 and January 2009. Inclusion criteria were good general health without severe general and local medical or psychological conditions (as reported by the patients), and edentulous maxillary and mandibular dental arches for at least three months (Fig. 1).

All subjects provided informed consent for the clinical procedures, in accordance with the Helsinki declaration and the Italian law. Five years extended warranty for the restorations was offered in case of failure. All subjects had confirmed their informed consent already provided to the clinical procedures in conformity with current guidelines for good clinical practice (12).

An independent operator, who did not participate in the original prosthetic procedures, performed all evaluations.

The survival rate was defined as surviving fixed dental prostheses minus altered fixed dental 
prostheses according to grades 2 and 3 of the three grade scale of chipping fractures (13). Both grades indicate that the alteration of the veneer surface cannot be polished without altering the original anatomic form. In contrast, grade 1 of chipping fractures is used if the altered surface does not involve a functional area and with polishing it is possible to maintain the original anatomy.

\section{Clinical procedures for FMIZBRs}

Four to six dental implants (Titanmed, Milde Implants, Bergamo, Italy) were placed in each of the jaws of each patient in a one-stage surgical procedure with the aid of a surgical guide (Fig. 2). Primary stability, with an implant stability quotient (ISO) (14) of 65 at least, was obtained for all the implants. With the use of a rubber dam for isolation, autopolymerized acrylic resin (Takilon BB, Salmoiraghi srl, Melegnano, Lodi, Italy) was used to isolate the gingiva and to record the location of the titanium temporary abutments (Cylinder, Milde Implants, Bergamo, Italy). All the implants were immediately loaded with an acrylic screw-retained interim prosthesis. The patients were instructed to remain on a soft diet for the subsequent two weeks. After two months, all implants showed good osseointegration at clinical, instrumental (resonance frequency analysis) and radiographic tests.

Using a pick-up technique, polyether completearch impression (Impregum/Permadyne, 3M ESPE AG, Seefeld, Germany)wasperformed ina customized open tray (Apex trays, Megadenta Dentalprodukte Radeberg, Germany). A plaster model (Esthetic-base gold, Dentona AG, Dormund, Germany) was made and used to obtain an anatomical contour wax-up. Soft tissue was reproduced in the impression using vinylpolysiloxane (Gingifast Rigid; Zhermack, Rovigo, Italy). The maxillary relation was taken with a postural facebow (15). The occlusal vertical dimension and an interocclusal centric relation were transferred to the articulator using occlusal rims.

Afterward, a verification device was fabricated intraorally to evaluate the accuracy of the definitive cast. Impression copings were connected to the abutments and splinted to each other with acrylic resin (Duralay, Reliance, Dental Mfg. Co. Worth, IL). The verification jig was sectioned and reconnected, unscrewed, and transferred to the definitive cast. Passive fit of the index on the definitive cast was confirmed, and the accuracy of the definitive cast was verified. The wax contour was then impressed on the plaster model.

The plaster model, the silicone mask, and then both components together were scanned with a laser scanner (Dental Wings series 3, Dental Wings Inc., Montreal, Canada). The zirconia core was designed with respect to the ceramic support and directly screwed on 1 to $4 \mathrm{~mm}$ shoulder multiunit abutments implant connection (3dObjects, Taverne, Switzerland). Using a reverse engineering technique, the STL files were transformed in JGESS files (Geomagic, Research Triangle Park, NC, USA) and modified by using a CAD system (Rhinoceros, Seattle, WA, USA).

For all prostheses, the zirconia core was devised also considering the veneering ceramic. The core was covered by a uniform thickness of veneering ceramic, and a maximum of $2 \mathrm{~mm}$ of unsupported porcelain was allowed. The connectors within the crowns were designed with a $10 \mathrm{~mm}^{2}$ area at least, as measured by the software used for the CAD technique. A Computer Aided Manufacturing (CAM) system was used to mill the zirconia core in the pre-sintered state (Zirite, Keramo, Tavernerio, Como, Italia). The cores were then sintered (3dObjects, Taverne, Switzerland), and covered by feldspathic porcelain (CZR Noritake Kizai Co. Ldt, Nagoya, Japan). Porcelain fusion was made with zirconium oxide margins by a single master ceramist (SST Dental Clinic, Milano, Italia), following a slow cooling protocol $(16,17)$.

The passive fit of the fixed detachable prostheses on the abutments was evaluated in three ways. First, pressure was applied first on one end abutment and then on the other one (18) to look for movement of the prostheses. A visual check was then carried out, and fit was evaluated with an explorer (19). Passivity was verified with an individual screw (20) in both sides of the end abutments. No movement of the restoration was noticed at finger sensibility, and the restoration remained in its position at the opposite unscrewed end abutment. The fit between the prostheses and all abutments was clinically verified in three dimensions (21). By using 8-mm-wide, 8-mm-thick shim stock foils (Hanel, Roeko, D-89122 Langenau, Germany), occlusal contacts were tested in maximum intercuspation without interferences in lateral excursions, and adjusted as necessary.

All prostheses were polished and lustered before final insertion by using a pearl surface paste (Noritake Kizai Co. Ldt, Nagoya, Japan). According to a previously standardized protocol (22), all patients were submitted to functional analysis of their masticatory muscles after the detachable prostheses were hand screwed in the mouth (Fig. 3). At the achievement of a good neuromuscular equilibrium $(23,24)$, the screw access holes were filled with gutta percha (Temporary stopping, GC) followed by light-cured composite resin (Filtek Z250, 3M ESPE).

\section{Follow-up evaluation}

Clinical events were recorded as irreversible events (failures) or as reversible/ adjustable events (complications) (25). Failures require the replacement or removal of the prosthesis; the causes could be fractures, loss of retention of the prosthesis, loss of osseointegration of the implant, persistent pain. Technical (loss of retention, crown fractures) and biological (periodontal/ 
implants problems, tenderness, temporary pain) complications were resolved without changing the prosthesis. In addition to the clinical examination, the patients were interviewed, and their satisfaction with the prosthetic treatment was rated from 0 ('not satisfied at all') to 3 ('completely satisfied'). They were also asked about recommending or not the treatment to someone else.

\section{RESULTS}

At the 5-year follow up visit, all restorations remained in situ and were still in use.

There were no failures recorded during the followup period. All the ten FMIZBRs that were followed up for 5 years experienced no biological complications. Eight FMIZBRs experienced some type of technical complications. Among complications there were minor porcelain veneer fractures that were easily polished (Fig. 4). The fractures occurred on different surfaces and were randomly distributed. None of the fractures impaired function or aesthetics. All complications were independent from the number of implants present in the mouth. No framework fractures were noted and none of the restorations were in need of repair or replacement-indicating a $100 \%$ survival rate.

The patients were fully satisfied with the treatment. All patients answered that they would recommend this treatment to another patient.

\section{DISCUSSION}

Different materials (metal, acrylic-metal, ceramiczirconia, ceramic) were studied to offer different options to patients and dentists to choose from. With different percentages, all of them have shown complications that could be summarized with:

- Fractures of the resin facing or teeth $(26,27)$;

- Fractures of titanium (more frequent) or gold framework (28);

- Excessive wear of the resin teeth $(29,30)$;

- Inflammation of soft tissues (28);

- Veneering material chipping (5-7).

The final choice for the single patient has to be addressed considering clinical necessity linked with biological and technical difficulties. Consequently, prognosis and economic patient cost have to be related to mid-long term results. The results in this preliminary report, where no framework fractures were noted and all restorations were still in function after 5 years, are in accordance with the absence of complete failure risk for implant supported restorations $(5,6)$.

The veneering porcelain, however, is subjected, we believe, to loads that exceed its load-bearing capacity when the restoration is supported by implants, resulting more frequently in chip-off fractures $(11,31,32)$. The good results of the implant support (no zirconia fractures) seem to be counterbalanced by the negative effects on the chipping. After all, the veneering material chipping fractures recorded in the present group of patients did not affect function or aesthetics. They all could be adjusted by polishing, without replacement of the prostheses. The patients were very satisfied with the treatment, and the presence of this minor complication should not be over-estimated.

To put it briefly the type of veneering material and technique used do not fully explain the veneering material fractures. Instead there is increasing evidence that the design of the core/framework supporting the veneering material seems to be critical to avoid fractures. If the veneering material is unsupported the risk of fracture is significantly increased $(12,17,18)$. This is associated with another important factor-the thickness of the veneering material. The authors started more than 10 years ago to manage zirconia for dental restoration and they have never forgotten what they learned from metal framework where the customized thickness of support is the success key for the veneering material (7). Moreover, there is increasing evidence that the design of the core/ framework supporting the veneering material is crucial to avoid fractures (11).

It has to be mentioned that for the last two years a novel technique has been approaching the Zirconia based restorations (ZBRs). It uses zirconia monoblocks and the entire restoration is machined with CAD-CAM technology (31). This approach seems to increase fracture resistance and reduce veneering chipping (32). Moreover it may reduce the occlusal wear of an antagonistic tooth in comparison to feldspathic dental porcelain restoration (33). In vitro studies demonstrate that it can prevent chipping (34). The dark side of this approach is that light transmission is reduced, and this can compromise the esthetic outcome of the prosthesis. Indeed, the lack of medium-long term clinical studies reduces the actual significance of this novel approach. At the moment, the use of pre-sinterized zirconia frameworks seems to be the best solution for complex oral rehabilitations.

Obviously, long-term studies involving a larger number of patients than those analyzed in this preliminary report must be carried out using zirconia/ ceramic implant-supported, full-arch fixed restorations.

\section{CONCLUSION}

Results from this pilot study suggest that FMIZBRs can be a treatment option that is rapidly shaping the coming dental rehabilitation area on implants. The survival rate of the restorations as well as patient satisfaction are very good, despite the occurrence of veneering material chipping. Further studies, including a larger number of patients, are necessary to better understand the interlink between the technical characteristics of the prostheses, clinical necessities, and biological responses. 


\section{Bibliography}

1. Tan T, Pjetursson BE, Lang NP, Chan ES. A systematic review of the survival and complication rates of fixed partial dentures (FDPs) atter an obsenvation period of at least 5 years. Clin Oral Impl Res. 2004;15(6):654-666.

2. Lygre H. Prosthodontic biomaterials and adverse reactions: a critical review of the clinical and research literature.Acta Odontol Scand. 2002;60(1):1-9.

3. Raigrodski AJ, Hillstead MB, Meng GK, Chung KH. Sunvival and complication rates of zirconia-based fixed dental prostheses: A systematic review.J Prosthet Dent.2012;107(3):170-177.

4. Papaspyridakos P, Lal K. Computer-assisted design/computerassisted manufacturing zirconia implant fixed complete prostheses: Clinical results and technical complications up to 4 years of function. Clin Oral Implants Res. 2013;24(6):659-665.

5. Larsson C, Vult von Steyern P. Five-year follow-up of implantsupported Y-TZP and ZTA fixed dental prostheses. A randomized, prospective clinical trial comparing two different material systems. Int $J$ Prosthodont. 2010;23(6):555-561.

6. Larsson C, Vult von Steyern P, Nilner K. A prospective study of implant-supported full arch-yttria-stabilized tetragonal zirconia polycrystal mandibular fixed dental prostheses: three-year results. Int J Prosthodont. 2010;23(4):364-369.

7. Tartaglia GM, Sidoti E, Sforza C. A 3-year follow-up study of allceramic single and multiple crowns performed in a private practice: a prospective case series. Clinics (Sao Paulo). 2011;66(12):2063-2070.

8. Tan JP, Sederstrom D, Polansky JR, McLaren EA, White SN. The use of slow heating and slow cooling regimens to strengthen porcelain fused to zirconia.J Prosthet Dent. 2012;107(3):163-169.

9. Chaar MS, Witkowski S, Strub JR, Att W. Effect of veneering technique on the fracture resistance of zirconia fixed dental prostheses. J Oral Rehabil. 2013;40(1):51-59.

10. Beuer $F$, Schweiger J, Eichberger M, Kappert HF, Gernet $W$, Edelhoff D. High-strength CAD/CAM-fabricated veneering material sintered to zirconia copings - a new fabrication mode for all-ceramic restorations. Dent Mater. 2009;25(1):121-128.

11. Larsson C, Von Steyern PV. Implant-supported full-arch zirconiabased mandibular fixed dental prostheses. Eight-year results from a clinical pilot study.Acta Odontol Scand. 2013;71(5): 1118-1122.

12. ICH E6 Good Clinical Practice: Consolidated Guidance. U.S. Food and Drug Administration http://www.fda.gov/ ScienceResearch/SpecialTopics/RunningClinicalTrials/ GuidancesInformationSheetsandNotices/ucm219488.htm 1966

13. Anusavice KJ. Standardizing failure, success, and survival decisions in clinical studies of ceramic and metalceramic fixed dental prostheses. Dent Mater. 2012;28(1):102-111..

14. Sennerby L, Meredith N. Implant stability measurements using resonance frequency analysis: biological and biomechanical aspects and clinical implications. Periodontology 2000. 2008;47:51-66.

15. Ferrario VF, Sforza C, Serrao G, Schmitz JH. Three-dimensional assessment of the reliability of a postural face-bow transfer.J Prosthet Dent. 2002;87(2):210-215.

16. Guazzato M, Walton TR, Franklin W, Davis G, Bohl C, Klineberg I. Influence of thickness and cooling rate on development of spontaneous cracks in porcelain/zirconia structures. Aust Dent J. 2010;55(3):306-310.

17. Schimtter M, Mussotter K, Rammelsberg $\mathrm{P}$, Gabbert 0 , Ohlmann B. Clinical performance of long-span zirconia frameworks for fixed dental prostheses: 5-year results.J Oral Rehabil.2012;39(7):552-557. 18. Henry PJ.An alternate method for the production of accurate cast and occlusal records in the osseointegrated implant rehabilitation. J Prosthet Dent. 1987;58(6):694-697.

19. Yanase RT, Binon PP, Jemt T, Gulbransen HJ, Parel S. Current Issues Forum. How do you test a cast framework for a full arch fixed implant supported prosthesis? Int J Oral Maxillofac Implants. 1994;9(4):469-474. 20. Tan KB, Rubenstein JE, Nicholls Jl, Youdelis RA. Three-dimensional analysis of the casting accuracy of one piece, osseointegrated implant retained prostheses. IntJ Prosthodont. 1993;6(4):346-363.

21. HollenderL,RocklerB. Radiographicevaluation of osseointegrated implants of the jaws. Experimental study of the influence of radiographic techniques on the measurement of the relation between implant and bone. Dentomaxillofac Radiol. 1980;9(2):91-95.

22. Ferrario VF, Sforza C, Colombo A, Ciusa V. An electromyographic investigation of masticatory muscles symmetry in normo-occlusion subjects.J Oral Rehabil. 2000;27(1):33-40.

23. Ferrario VF, Tartaglia GM, Galletta A, Grassi GP, Sforza C. The influence of occlusion on jaw and neck muscle activity: a surface EMG study in healthy young adults. J Oral Rehabil. 2006;33(5):341-348.

24. Tartaglia GM, Testori T, Pallavera A, Marelli B, Sforza C. Electromyographicanalysis of masticatoryand neck muscles in subjects with natural dentition, teeth-supported and implant-supported prostheses. Clin Oral Implants Res. 2008;19(10):1081-1088.

25. Ortorp A, Kihl ML, Carlsson GE. A 5-year retrospective study of sunvival of zirconia single crowns fitted in a private clinical setting. J Dent. 2012;40(6):527-530.

26. Ortorp A, Jemt T. Clinical experiences of computer numeric control-milled titanium frameworks supported by implants in the edentulous jaw: a 5-year prospective study. Clin Implant Dent Relat Res. 2004;6(4):199-209.

27. Duncan JP, Nazarova E, Vogiatzi T, Taylor TD. Prosthodontic complications in a prospective clinical trial of single-stage implants at 36 months. Int J Oral Maxillofac Implants. 2003;18(4):561-565.

28. Ortorp $A$, Jemt $T$. Early laser-welded titanium frameworks supported by implants in the edentulous mandible: a 15-year comparative follow-up study. Clin Implant Dent Relat Res. 2009;11(4):311-322.

29. Purcell BA, McGlumphy EA, Holloway JA, Beck FM. Prosthetic complications in mandibular metal-resin implant-fixed complete dental prostheses: a 5- to 9-year analysis. Int J Oral Maxillofac Implants. 2008;23(5):847-857.

30. Bozini T, Petridis H, Garefis K. A meta-analysis of prosthodontic complication rates of implant-supported fixed dental prostheses in edentulous patients after an observation period of at least 5 years. Int J Oral Maxillofac Implants. 2011;26(2):304-318.

31. Rojas-Vizcaya F. Full zirconia fixed detachable implant-retained restorations manufactured from monolithic zirconia: clinical report after two years in senvice.J Prosthodont. 2011;20(7):570-576.

32. Beuer F, Stimmelmayr M, Gueth JF, Edelhoff D, Naumann M. In vitro performance of full-contour zirconia single crowns. Dent Mater. 2012;28(4):449-456.

33. Zhang Y, Chai H, Lee JJ, Lawn BR. Chipping resistance of graded zirconia ceramics for dental crowns.J Dent Res. 2012;91(3):311-315. 34. Jung YS, Lee JW, Choi YJ, Ahn JS, Shin SW, Huh JB. A study on the in-vitro wear of the natural tooth structure by opposing zirconia or dental porcelain.J Adv Prosthodont. 2010;2(3):111-115. 